\title{
The Consequences of Thermal Radiation and Chemical Reactions on Magneto-hydrodynamics in Two Dimensions Over a Stretching Sheet with Jeffrey Fluid.
}

\author{
Vijay Patel ${ }^{1}$ and Jigisha Pandya ${ }^{2}$ \\ ${ }^{1}$ LDRP Institute of Technology and Research \\ ${ }^{2}$ Sarvajanik College of Engineering and Technology
}

December 9, 2021

\begin{abstract}
In this research paper, the Homotopy Analysis Method is used to investigate the twodimensional electrical conduction of a magneto-hydrodynamic (MHD) Jeffrey Fluid across a stretching sheet under various conditions, such as when electrical current and temperature are both present, and when heat is added in the presence of a chemical reaction or thermal radiation. Applying similarity transformation, the governing partial differential equation is transformed into terms of nonlinear coupled ordinary differential equations. The Homotopy Analysis Method is used to solve a system of ordinary differential equations. The impact of different numerical values on velocity, concentration, and temperature is examined and presented in tables and graphs. The fluid velocity reduces as the retardation time parameter(2) grows, while the fluid velocity inside the boundary layer increases as the Deborah number () increases. The velocity profiles decrease when the magnetic parameter M is increased. The results of this study are entirely compatible with those of a viscous fluid. The Homotopy Analysis Method calculations have been carried out on the PARAM Shavak high-performance computing (HPC) machine using the BVPh2.0 Mathematica tool.
\end{abstract}

\section{Hosted file}

VijayWiley.pdf available at https://authorea.com/users/450348/articles/548671-theconsequences-of-thermal-radiation-and-chemical-reactions-on-magneto-hydrodynamics-intwo-dimensions-over-a-stretching-sheet-with-jeffrey-fluid 